\title{
Dilated Intercellular Spaces and Chronic Cough As an Extra- oesophageal Manifestation of Gastrooesophageal Reflux Disease
}

\author{
Roy C. Orlando, MD \\ Mary Kay and Eugene Bozymski and Linda and William Heizer Distinguished Professor of \\ Medicine, and Adjunct Professor of Cell and Molecular Physiology, University of North Carolina \\ School of Medicine, 103 Mason Farm Road, CB\#7032; MBRB, Rm 7312c, Chapel Hill, North \\ Carolina, 27599, USA, Tel:(01) 919-843-4583, Fax: (01) 919-843-6899, rorlando@med.unc.edu
}

\begin{abstract}
Chronic cough is one of the extra-oesophageal manifestations of gastrooesophageal reflux disease (GORD). It is presumed to occur either directly by microaspiration of acidic gastric contents into the airway or indirectly by a reflex triggered by contact of acidic refluxates with the oesophageal epithelium in GORD. How contact of the oesophageal epithelium with acidic refluxates promotes sensitization for chronic cough is unknown, but like heartburn, which is a necessary accompaniment, it requires acid activation of nociceptors within the oesophageal mucosa. Dilated intercellular spaces within the oesophageal epithelium, a reflection of an increase in paracellular permeability, is a histopathologic feature of both erosive and nonerosive forms of GORD. Since it correlates with the symptom of heartburn, it is hypothesized herein that the increase in paracellular permeability to acid reflected by dilated intercellular spaces in oesophageal epithelium also serves as mediator of the signals that produce the reflex-induced sensitization for cough - a sensitization that can occur centrally within the medullary Nucleus Tractus Solitarius or peripherally within the tracheobronchial tree.
\end{abstract}

\section{Keywords}

sensitization; paracellular permeability; vagus nerve; substance P; TRPV1

\section{Introduction}

Gastrooesophageal reflux disease (GORD) is a disorder that commonly results in recurrent heartburn. A subset with GORD also experiences chronic cough, and as such chronic cough has been acknowledged as an extraoesophageal manifestation of GORD[1]. The mechanism(s) by which GORD induces chronic cough is unclear. However, two distinct mechanisms have been proposed: one is direct and due to the microaspiration of acidic refluxates into the airway and the other is indirect and due to a neural reflex triggered by the contact of oesophageal epithelium with acidic refluxates[2]. The mechanism by which the latter occurs remains unknown, but the necessity for it to occur in those with heartburn

\footnotetext{
(C) 2010 Elsevier Ltd. All rights reserved.

Correspondence to: Roy C. Orlando.

Publisher's Disclaimer: This is a PDF file of an unedited manuscript that has been accepted for publication. As a service to our customers we are providing this early version of the manuscript. The manuscript will undergo copyediting, typesetting, and review of the resulting proof before it is published in its final citable form. Please note that during the production process errors may be discovered which could affect the content, and all legal disclaimers that apply to the journal pertain.
} 
suggests a common pathway. It is currently well recognized that the oesophageal epithelium in those with heartburn have a lesion known as dilated intercellular spaces (DIS)[3-7]. How the presence of this lesion could also contribute to the reflex for cough is herein described.

\section{Results and Discussion}

Gastrooesophageal reflux is a physiologic phenomenon that brings acidic gastric contents into daily contact with the oesophageal epithelium. In some subjects, this contact is pathologic in that it leads to tissue injury. Tissue injury in oesophagus is heralded clinically by the symptom of heartburn[1]. Heartburn is typically a substernal burning discomfort that begins in the epigastrium and rises toward the throat. It is worse after meals and upon reclining and relieved by substances such as antacids and baking soda that buffer gastric acid. The morphologic expression of tissue injury giving rise to heartburn varies greatly from microscopic to macroscopic lesions. The typical macroscopic lesions that occur when reflux damages the oesophageal epithelium are erosions and this in association with erythema and friability due to inflammation. This condition is commonly referred to as erosive (or reflux) oesophagitis. The typical microscopic lesions that occur when reflux damages the oesophageal epithelium are basal cell hyperplasia, elongation of the rete pegs (extensions of epithelium into underlying lamina propria) and DIS[3,8]. Basal cell hyperplasia and elongation of the rete pegs are readily appreciated on light microscopy of hematoxylin and eosin stained sections of oesophageal epithelium while DIS are best appreciated on transmission electron microscopy (Figure 1). Notably, these same lesions are identifiable in biopsies of oesophageal epithelium in those with erosive oesophagitis supporting macroscopic disease as having progressed from microscopic disease. On upper endoscopy macroscopic disease (erosions) can be found in about one-third of patients with heartburn, the remaining patients having what appears to be normal-appearing oesophageal mucosa. Those with heartburn and normal-appearing oesophageal mucosa have microscopic disease on biopsy and are commonly referred to as having non-erosive reflux disease (NERD).

Based on experimental studies in animals and humans, DIS is the earliest morphologic sign of acid injury to oesophageal epithelium. It has been shown to be a relatively sensitive but not a specific marker of NERD[9]. It can be produced by acid perfusion of healthy oesophageal epithelium, correlates with the symptom of heartburn in GORD, and resolves along with heartburn when GORD subjects are treated with proton pump inhibitor (PPI) therapy, i.e. intercellular space diameters are restored to normal[10-13]. The development of DIS reflects an altered apical junctional complex, primarily tight junctions and adherens junctions, the regulators of paracellular permeability. Consequently, the appearance of DIS reflects an increase in paracellular permeability, i.e. an increase in the diffusion of ions and molecules from the lumen into the intercellular space[14]. In particular high concentrations of chloride ions in acidic refluxates diffuse in sufficient quantities to create an osmotic gradient that pulls water into the area. It is the hydrostatic force resulting from excess water movement into the intercellular space that accounts for the separation of adjacent cell membranes and the appearance of DIS. Support for this concept is provided experimentally by the observation that DIS do not occur in acid-damaged oesophageal epithelium if the osmotic force for water movement into the intercellular space is negated by balancing the chloride concentrations on both sides of the tissue[15].

Given the close relationship between DIS, increased paracellular permeability and heartburn[9], the following concept has been proposed to explain the mechanism by which acidic refluxates in GORD, but not healthy, subjects precipitates the symptom of heartburn. 
In GORD subjects there is acid injury to the apical junctional complex that increases paracellular permeability, and the presence of increased paracellular permeability leads to an excess 'leak' of luminal contents, including refluxed gastric acid into the intercellular space. Acidification of the intercellular space even modestly, i.e. reduction of intercellular $\mathrm{pH}$ to 56 , is sufficient to trigger activation of such acid-sensitive nociceptors within the oesophageal mucosa as transient receptor potential vanilloid-1 (TRPV-1) and/or acid sensing ion channels-type $3[16,17]$. These in turn transmit signals of sufficient magnitude to the central nervous system for cortical recognition of the symptom of heartburn[18].

Notably the oesophageal acid-activated areas within the brain include the insula, prefrontal and anterior cingulate gyrus, primary and secondary sensorimotor and parieto-occipital cortices[19]. As in GORD, acid exposure to the oesophageal epithelium of healthy subjects activates acid-sensitive nocieptors within the mucosa; and as in GORD, these signals are transmitted to similar areas of the central nervous system. In contrast to GORD, however, healthy subjects do not experience heartburn, and this explainable by the fact that the signals reaching the central nervous system are both delayed in onset and lower in magnitude than those observed in GORD[19]. These observations support the effectiveness of the oesophageal epithelium to act as a barrier against acid access to the nociceptors within the oesophageal mucosa of healthy subjects.

Moreover, these concepts can be extended and herein are proposed as a means by which contact of the oesophageal epithelium with acidic refluxates in GORD, but not healthy subjects, promotes such extraoesophageal manifestitations of GORD as chronic cough.

Specifically, the oesophageal signals responsible for heartburn are of sufficient magnitude to reflexively activate Vagal pathways to the medullary Nucleus Tractus Solitarius (NTS) and beyond to the oesophagus' embryologic relative the tracheobronchial tree (Figure 2). These signals either centrally via the NTS or peripherally via the tracheobronchial tree are capable of sensitizing the airways for cough[20-24]; and key among the mediators of the central and peripheral sensitization for cough are the release of tachykinins, especially substance $\mathrm{P}[20$ 23].

Indeed, experimental acid perfusion in the guinea pig oesophagus has been shown to release substance $\mathrm{P}$ within the airway and this to induce airway inflammation[22,23]. In addition, oesophageal acidification in the cat has also been shown to increase mucus secretion, increase bronchial smooth muscle hyperactivity, and decrease mucociliary clearance[24]. While these changes are significant and measurable experimentally, the fact that acid reflux sensitizes, rather than triggers, chronic cough is an important concept. This is because it helps explain why chronic cough doesn't develop in the vast majority of GORD patients despite pathologic levels of oesophageal acidity, why chronic cough may not correlate with acid reflux events on $\mathrm{pH}$ monitoring, and why chronic cough may remain unaffected when acid reflux is controlled in GORD patients by either medical or surgical means[25-28]. In effect, chronic cough may not occur in GORD because of the lack of a, yet undefined, but required central or peripheral mechanism for sensitization for cough or the lack of a means of triggering cough in an individual with GORD who is already sensitized for cough.

Moreover, since sensitization may occur centrally where there is a convergence of neural inputs from a variety of peripheral sites - oropharynx, larynx, oesophagus, tracheobronchial tree - therapeutic control of one process such as reflux is unlikely to be sufficient to relieve chronic cough. 


\section{Conclusions}

Chronic cough is one of the extra-oesophageal manifestations of GORD. It can occur by a vagally-mediated reflex initiated by exposure of the oesophagus to acid. Such exposure in predisposed individuals can sensitize the tracheobronchial tree to cough either through a central or peripheral mechanism mediated by release of substance $P$ and other tachykinins. Here we hypothesize that acid reflux initiates this reflex by accessing oesophageal nociceptors through the same (paracellular) pathway responsible for heartburn, and that central perception of heartburn identifies those in whom peripheral (oesophageal) signaling is of sufficient magnitude to activate the reflex. Activation of the reflex may occur centrally as well as peripherally and this may explain why treatment of any one modality, e.g. acid reflux with proton pump inhibitors, has proven of limited value in the relief of cough. Additional research will be needed to confirm these hypotheses.

\section{References}

1. Orlando, RC. Reflux esophagitis. In: Yamada, T.; Alpers, D.; Owyang, C., et al., editors. Textbook of Gastroenterology. Philadelphia: JB Lippincott Williams \& Wilkins; 1999. p. 1235-1263.

2. Kollarik M, Brozmanova M. Cough and gastroesophageal reflux: Insights from animal models. Pulm Pharmacol Ther. 2008

3. Tobey NA, Carson JL, Alkiek RA, Orlando RC. Dilated intercellular spaces: a morphological feature of acid reflux--damaged human esophageal epithelium. Gastroenterology. 1996; 111:12001205. [PubMed: 8898633]

4. Solcia E, Villani L, Luinetti O, Trespi E, Strada E, Tinelli C, Fiocca R. Altered intercellular glycoconjugates and dilated intercellular spaces of esophageal epithelium in reflux disease. Virchows Arch. 2000; 436:207-216. [PubMed: 10782878]

5. Farre R, De Vos R, Geboes K, Verbecke K, Vanden Berghe P, Depoortere I, Blondeau K, Tack J, Sifrim D. Critical role of stress in increased oesophageal mucosa permeability and dilated intercellular spaces. Gut. 2007; 56:1191-1197. [PubMed: 17272649]

6. Caviglia R, Ribolsi M, Maggiano N, Gabbrielli AM, Emerenziani S, Guarino MP, Carotti S, Habib FI, Rabitti C, Cicala M. Dilated intercellular spaces of esophageal epithelium in nonerosive reflux disease patients with physiological esophageal acid exposure. Am J Gastroenterol. 2005; 100:543548. [PubMed: 15743349]

7. Ravelli AM, Villanacci V, Ruzzenenti N, Grigolato P, Tobanelli P, Klersy C, Rindi G. Dilated Intercellular Spaces: A Major Morphological Feature of Esophagitis. J Pediatr Gastroenterol Nutr. 2006; 42:510-515. [PubMed: 16707972]

8. Ismail-Beigi FHP, Pope CE. Histological consequences of gastroesophageal refluxes in man. Gastroenterology. 1970; 58:163-174. [PubMed: 5413015]

9. Orlando LA, Orlando RC. Dilated intercellular spaces as a marker of GERD. Curr Gastroenterol Rep. 2009; 11:190-194. [PubMed: 19463218]

10. Bove M, Vieth M, Dombrowski F, Ny L, Ruth M, Lundell L. Acid challenge to the human esophageal mucosa: effects on epithelial architecture in health and disease. Dig Dis Sci. 2005; 50:1488-1496. [PubMed: 16110841]

11. Calabrese C, Bortolotti M, Fabbri A, Areni A, Cenacchi G, Scialpi C, Miglioli M, Di Febo G. Reversibility of GERD ultrastructural alterations and relief of symptoms after omeprazole treatment. Am J Gastroenterol. 2005; 100:537-542. [PubMed: 15743348]

12. Kahrilas PJ. Dilated intercellular spaces: extending the reach of the endoscope. Am J Gastroenterol. 2005; 100:549-550. [PubMed: 15743350]

13. Xue YZL, Lin S. The changes of esophageal epithelium intercellular spaces before and after omeprazole treatment in GERD patients. Gastroenterology. 2007; 132:A281.

14. Tobey NA, Hosseini SS, Argote CM, Dobrucali AM, Awayda MS, Orlando RC. Dilated intercellular spaces and shunt permeability in nonerosive acid-damaged esophageal epithelium. Am J Gastroenterol. 2004; 99:13-22. [PubMed: 14687135] 
15. Tobey NA, Gambling TM, Vanegas XC, Carson JL, Orlando RC. Physicochemical basis for dilated intercellular spaces in non-erosive acid-damaged rabbit esophageal epithelium. Dis Esophagus. 2008; 21:757-764. [PubMed: 18522636]

16. Bielefeldt K, Davis BM. Differential effects of ASIC3 and TRPV1 deletion on gastroesophageal sensation in mice. Am J Physiol Gastrointest Liver Physiol. 2008; 294:G130-G138. [PubMed: 17975130]

17. Mathews PJAQ, Facer P, Davis JB, Thompson DG, Anand P. Increased capsaicin receptor TRPV1 nerve fibers in the inflammed human esophagus. Eur J Gastroenterol Hepatol. 2004; 16:897-902. [PubMed: 15316415]

18. Barlow WJ, Orlando RC. The pathogenesis of heartburn in nonerosive reflux disease: a unifying hypothesis. Gastroenterology. 2005; 128:771-778. [PubMed: 15765412]

19. Kern M, Hofmann C, Hyde J, Shaker R. Characterization of the cerebral cortical representation of heartburn in GERD patients. Am J Physiol Gastrointest Liver Physiol. 2004; 286:G174-G181. [PubMed: 14512287]

20. Chen CY, Joad JP, Bric J, Bonham AC. Central mechanisms I: plasticity of central pathways. Handb Exp Pharmacol. 2009:187-201. [PubMed: 18825341]

21. Bonham AC, Sekizawa S, Chen CY, Joad JP. Plasticity of brainstem mechanisms of cough. Respir Physiol Neurobiol. 2006; 152:312-319. [PubMed: 16554189]

22. Hamamoto J, Kohrogi H, Kawano O, Iwagoe H, Fujii K, Hirata N, Ando M. Esophageal stimulation by hydrochloric acid causes neurogenic inflammation in the airways in guinea pigs. $\mathrm{J}$ Appl Physiol. 1997; 82:738-745. [PubMed: 9074957]

23. Kohrogi H, Hamamoto J, Kawano O, Iwagoe H, Fujii K, Hirata N, Ando M. The role of substance P release in the lung with esophageal acid. Am J Med. 2001; 111 Suppl 8A:25S-30S. [PubMed: 11749920]

24. Lang IM, Haworth ST, Medda BK, Roerig DL, Forster HV, Shaker R. Airway responses to esophageal acidification. Am J Physiol Regul Integr Comp Physiol. 2008; 294:R211-R219. [PubMed: 17928508]

25. Smith JA, Decalmer S, Kelsall A, McGuinness K, Jones H, Galloway S, Woodcock A, Houghton LA. Acoustic cough-reflux associations in chronic cough: potential triggers and mechanisms. Gastroenterology. 139:754-762. [PubMed: 20600028]

26. Javorkova N, Varechova S, Pecova R, Tatar M, Balaz D, Demeter M, Hyrdel R, Kollarik M. Acidification of the oesophagus acutely increases the cough sensitivity in patients with gastrooesophageal reflux and chronic cough. Neurogastroenterol Motil. 2008; 20:119-124. [PubMed: 17999650]

27. Haque RA, Usmani OS, Barnes PJ. Chronic idiopathic cough: a discrete clinical entity? Chest. 2005; 127:1710-1713. [PubMed: 15888850]

28. Chang AB, Lasserson TJ, Kiljander TO, Connor FL, Gaffney JT, Garske LA. Systematic review and meta-analysis of randomised controlled trials of gastro-oesophageal reflux interventions for chronic cough associated with gastro-oesophageal reflux. Bmj. 2006; 332:11-17. [PubMed: 16330475] 
Electron Micrographs of Normal and Dilated
Intercellular Spaces in Esophageal Epithelium

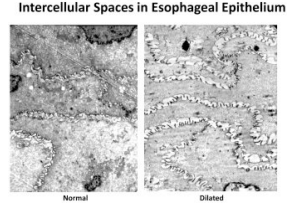

Figure 1.

Transmission electron photomicrographs of oesophageal epithelium in health and in gastrooesophageal reflux disease. The photomicrographs show that intercellular space diameters are relatively small in normal (healthy) oesophageal epithelium in contrast to an acid damaged oesophageal epithelium where there is a marked increase in intercellular space diameter. This abnormality in those with gastrooesophageal reflux disease has come to be known as 'dilated intercellular spaces', the lesion a reflection of an increase in paracellular permeability. X3000. 


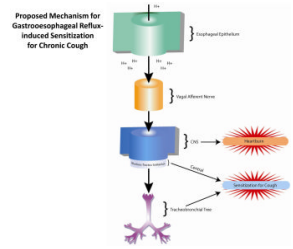

Figure 2.

Proposed mechanism for cough sensitization in gastrooesophageal reflux disease. Luminal acid diffuses through the paracellular pathway in oesophageal epithelium, the latter morphologically apparent as dilated intercellular spaces (Green). Acidification of the intercellular compartment triggers activation of vagal afferents (Orange) which transmit signals to the CNS for heartburn (Blue). In turn, a subset of those that experience heartburn will transmit efferent signals to the medullary Nucleus Tractus Solitarius or beyond to the tracheobronchial tree (Purple) that result in sensitization of the individual for cough. 